\title{
Sobre barbarie y series de TV. Una metáfora para pensar la alteridad cultural
}

On barbarism and TV series. A metaphor to think cultural otherness

\author{
Ariel Gómez Ponce ariel.gomezponce@fl.unc.edu.ar \\ http://orcid.org/0000-0001-8830-9544 \\ Universidad Nacional de Córdoba/ Consejo Nacional \\ de Investigaciones Científicas y Técnicas (Argentina)
}

\section{Resumen}

Nos interrogamos por el bárbaro, mitema que ha asimilado subjetividades-otras a un gregarismo y reducido comunidades históricas a la estandarización y homogeneidad étnica. A partir de la semiótica de Yuri Lotman, partiremos de considerar que esta figura responde a un mecanismo de "autodescripción" que, a través de la una disquisición intercultural, sirve más para reflexionar sobre la propia tensión interna que para explicar aquello que se encuentra fuera del sistema. Analizaremos el caso de dos series de TV (Animal Kingdom y Sons of Anarchy) en las cuales esta apropiación de la barbarie pone en cuestión una problemática actual acuciante: el orden familiar. Al atender a este entretejido, el bárbaro puede ser comprendido como un mecanismo ideológico complejo, funcional tanto para imponer un conjunto de representaciones de lo familiar (para normativizar y normalizar "lo heredado"), como también para ponerlas en discusión. Se trata de pensarlo no como una figura recluida a la historia, sino más bien como un operador cultural sumamente activo: una lógica de regulación ideológica en nuestras sociedades que rápidamente se asumen a sí mismas como racionales, pero que insisten en preguntarse por estos lugares comunes con lo animal que el arte parece siempre problematizar. 
Palabras clave: barbarie; series de TV; semiótica de la cultura; Yuri Lotman.

\begin{abstract}
This work questions about barbarians, a myth that has assimilated subjectivities-others to a gregarism and reduced historical communities to the standardization and ethnic homogeneity. In terms of Yuri Lotman's, we will consider that the figure of the barbarian responds to a mechanism of "self-description" that, through an intercultural disquisition, serves more to reflect on the internal tension itself than to explain what is outside the system. We will analyze two TV series (Animal Kingdom and Sons of Anarchy) in which this appropriation of barbarism calls into question a pressing current problem: the family order. In studying this aspect, barbarian can be understood as a complex, functional ideological mechanism to impose a set of representations of family (to normalize and to normativize "inherited" order), as well as to put them into discussion. We will then think of it not as a secluded figure in history, but rather as a highly active cultural operator: a logic of ideological regulation in our societies, which quickly assume themselves as rational, but insist on questioning in these common places with the animal that art always seems to problematize.
\end{abstract}

Keywords: barbarism; TV series; cultural semiotics; Yuri Lotman.

\title{
Sobre el bárbaro
}

Este trabajo se orienta a indagar sobre una zona de la producción artística que problematiza la pervivencia del bárbaro. Se trata de reflexionar sobre un estereotipo cultural incesante que, desde las culturas antagónicas a los pueblos griegos (aquellas que, según la etimología de la palabra, "balbuceaban") hasta las invasiones vikingas en el Medioevo, e incluso a través de la lectura de pueblos originarios como "buenos salvajes", conforma un mitema para el tratamiento de subjetividades que transitan tanto dominio colonial como etnocentrismo occidental. Por estos derroteros diacrónicos, el bárbaro aparece no solo como nomenclatura para comunidades históricas, sino además como un término exónimo: un lugar común para pensar alteridades que rememora, en sus múltiples emergencias, el antiguo problema de la extranjería que choca con la propia cultura.

Sin embargo, según la hipótesis del antropólogo Roger Bartra (2001), estudiar el fenómeno del bárbaro es, muy por el contrario, atender a un fenómeno derivado: es decir, implica comprender un mecanismo que, aunque convoque una disquisición intercultural de larga tradición, sirve más para reflexionar sobre la propia tensión interna que para explicar aquello 
que se encuentra fuera del sistema. Dicho de otro modo, Bartra asume que aquello que se pone en cuestión son las condiciones de posibilidad que determina cada cultura para calificar tal o cual sujeto-otro como un "bárbaro". Se trata también de un supuesto en diálogo con la propuesta del semiólogo ruso Yuri Lotman (1998[1993]), quien ha definido estos "procesos de barbarización" como un "mecanismo de autodescripción cultural": según el modo en que se relacionan con su exterioridad, las culturas construyen un punto de vista que les permite definirse, describirse y limitar su identidad. En consecuencia, la semiótica de la cultura, espacio del saber diseñado no solo como una ciencia de los signos sino como una "historia de la cultura", aparece como una reflexión compleja que permite captar estas modulaciones del bárbaro, en tanto brinda herramientas oportunas para su interpretación.

En el presente trabajo, partimos de considerar una de las hipótesis de Lotman (1990): que los textos del arte son aquellos que comportan mayor información al crear nuevos sentidos y modelos de la realidad y dinamizar las memorias de las culturas. Noción teórico-metodológica central en la perspectiva lotmaniana, el texto se compone entonces como un observatorio cultural, cuyo estudio expone una multiplicidad de organizaciones semióticas diferentes (variantes de forma, contenido, matrices genéricas y personajes, entre otros) que permiten entender la diacronía y la sincronía social (Lotman, 2000[1977]). En su dinamismo, ellos forman parte de un poliglotismo que define la cultura desde una heterogeneidad de lenguajes (tales como la literatura, la pintura, el teatro, el cine, la televisión), mostrando además variados procesos de percepción y construcción de la historia.

Con base en este presupuesto, intuimos que ciertos modos de leer "lo bárbaro" bucean en los textos de consumo masivo, presentándose como un lugar privilegiado para hacer emerger múltiples sentidos sociales de nuestra actualidad. Por ello, en investigaciones previas, nos ocupamos de explorar cómo la cultura contemporánea cartografía la insistencia de una estética bárbara: es decir, un entretejido de recurrencias y repeticiones que conforman un imaginario de representación visual (Gómez Ponce, 2016). Observamos entonces la descripción de un amplio número de objetos artísticos mainstream, tales como publicidades, muestras fotográficas, revistas de moda e incluso aquel look definido como "lumbersexual" (en referencia al término inglés lumberjack, es decir, leñador), fuertemente promovido de la mano de reconocidos modelos como Brock O'Hurn o Alexander Masson, pero replicado luego por un cúmulo de actores reconocidos que asumen la representación artística del bárbaro (aspecto que puede apreciarse en la Figura 1). 

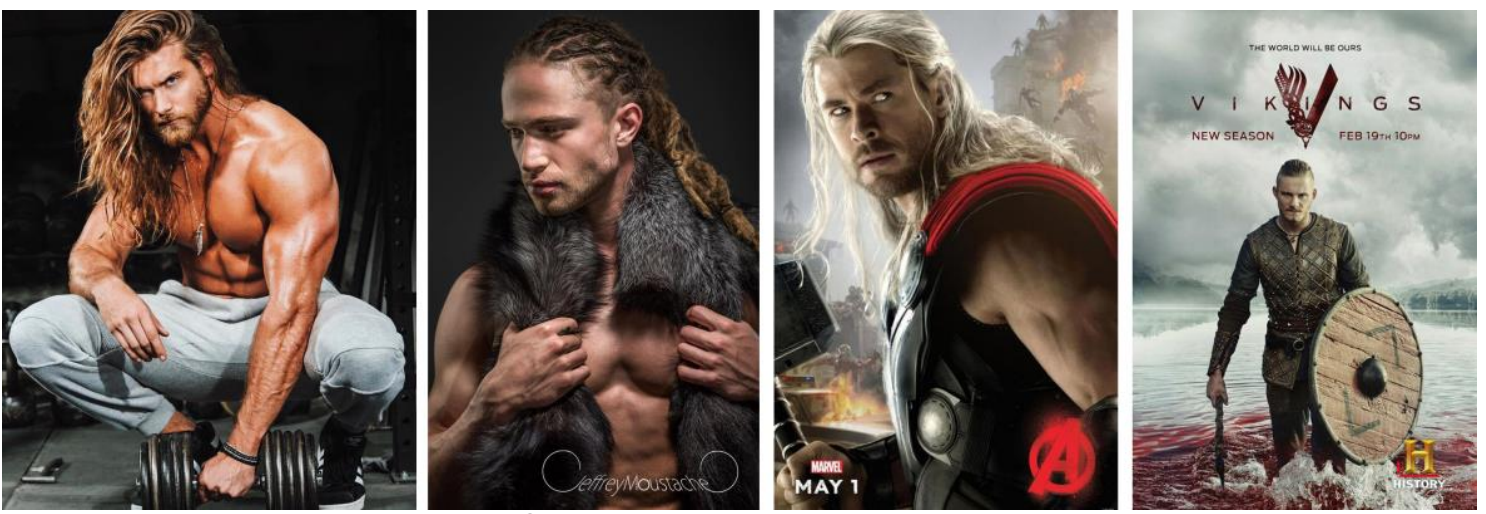

Figura 1. De izquierda a derecha: Brock O’Hurn, por Binais Begovic. Iron Man Magazine, Nro. Julio, Estados Unidos, 2016; Alexander Masson, por Jeffrey Moustache, Jeffrey Moustache Photography, Estados Unidos, 2015; póster promocional de Thor, película The Avengers, Estados Unidos, Marvel Studios, Paramount Pictures, 2012; póster promocional de la serie Viking. Eliza Mellor, Estados Unidos, Take 5 Productions, History Channel, 2016.

La pregunta que guio aquel rastreo (y sobre la cual intentamos arrojar luz en esta presentación) es por qué la cultura se esmera en recuperar un bárbaro que, remitiendo a una percepción del otro como sujeto primitivo o no-civilizado, invade el centro de la escena artística. Y desde el reciente auge cinematográfico del dios nórdico Thor en The Avengers (2012), hasta la inmensa profusión de filmes que refractan el enclave nórdico (Outlander, 2008; Valhalla Rising, 2009; Conan, The Barbarian, 2012; Northmen, 2014; o animaciones infantiles como How to Train Your Dragon, 2010), los textos audiovisuales parecen consagrarse como la esfera de reproducción privilegiada.

De manera especial, las series de TV han tomado también este lugar de reactivación cultural. Viene al caso señalar el éxito del reciente seriado Vikings (2013), ficción producida por la cadena de documentales History Channel que arrostra un intento por deconstruir el colectivo vikingo: es decir, mostrar la organización interna de su sociedad y sus tradiciones, como también las tensiones generadas por los vínculos interculturales. Y mientras otras series como True Blood (HBO, 2008-2013) optan por narrar historias de "vampiros bárbaros" dentro del enclave gótico y de un conjunto de monstruos que luchan por derechos civiles y sociales, relatos como Game of Thrones (HBO, 2011) se orientan a traducir una barbarie que, lejos de exhibir un caos social, expone un sistema sumamente jerárquico y estructurado, como sucede con la población ficcional de los dothraki.

A primera vista, estos textos parecen priorizar una discusión en torno a la conformación de la comunidad bárbara, subrayando la concreción de un cuerpo y una identidad colectiva ajena a lo civilizado. Por ello, si en indagaciones previas nos interesábamos por la replicación estéticocorporal del bárbaro, en esta oportunidad nos preguntamos por un imaginario que lee el 
bárbaro desde una tendencia para la formación de grupos. Dicho de otro modo, en los avatares de los textos de consumo masivo, gregarismo, barbarie y alteridad estarían conformando un entretejido de sumo interés que la ficción parece poner de relieve, ofreciendo una nueva descripción cultural, como bien observaremos seguidamente. Con el objeto de dar cuenta de ello, abordaremos el caso de dos series de TV: Sons of Anarchy (FX, 2008-2014) y Animal Kingdom (TNT, 2016).

Estas textualidades permitirán apuntar cómo la barbarie, leída como manada, deviene un mecanismo ideológico complejo, funcional tanto para imponer un conjunto de representaciones, como también para ponerlas en discusión. Incluso observaremos que la referencia a lo gregario esconde una crítica social de sumo interés: cómo la metáfora del bárbaro opera para describir el orden familiar, e incluso para normativizar y normalizar "lo heredado". Se trata de narraciones seriales que esbozan fuertemente, a través de alusiones a la barbarie, un estado de la cuestión sobre las condiciones sociopolíticas en un corte sincrónico de la cultura. Y no dudamos en que muchos otros textos podrían también ilustrar esto. Ocurre que las series son uno de los productos más consumidos en la actualidad. Durante el transcurso de la última década, afirman que la TV está lejos de ser una banal parcela de una "cultura de evasión": son, por el contrario, prismas que sintetizan sentidos y problemáticas que fluyen por los imaginarios culturales (Gómez Ponce, 2017). 

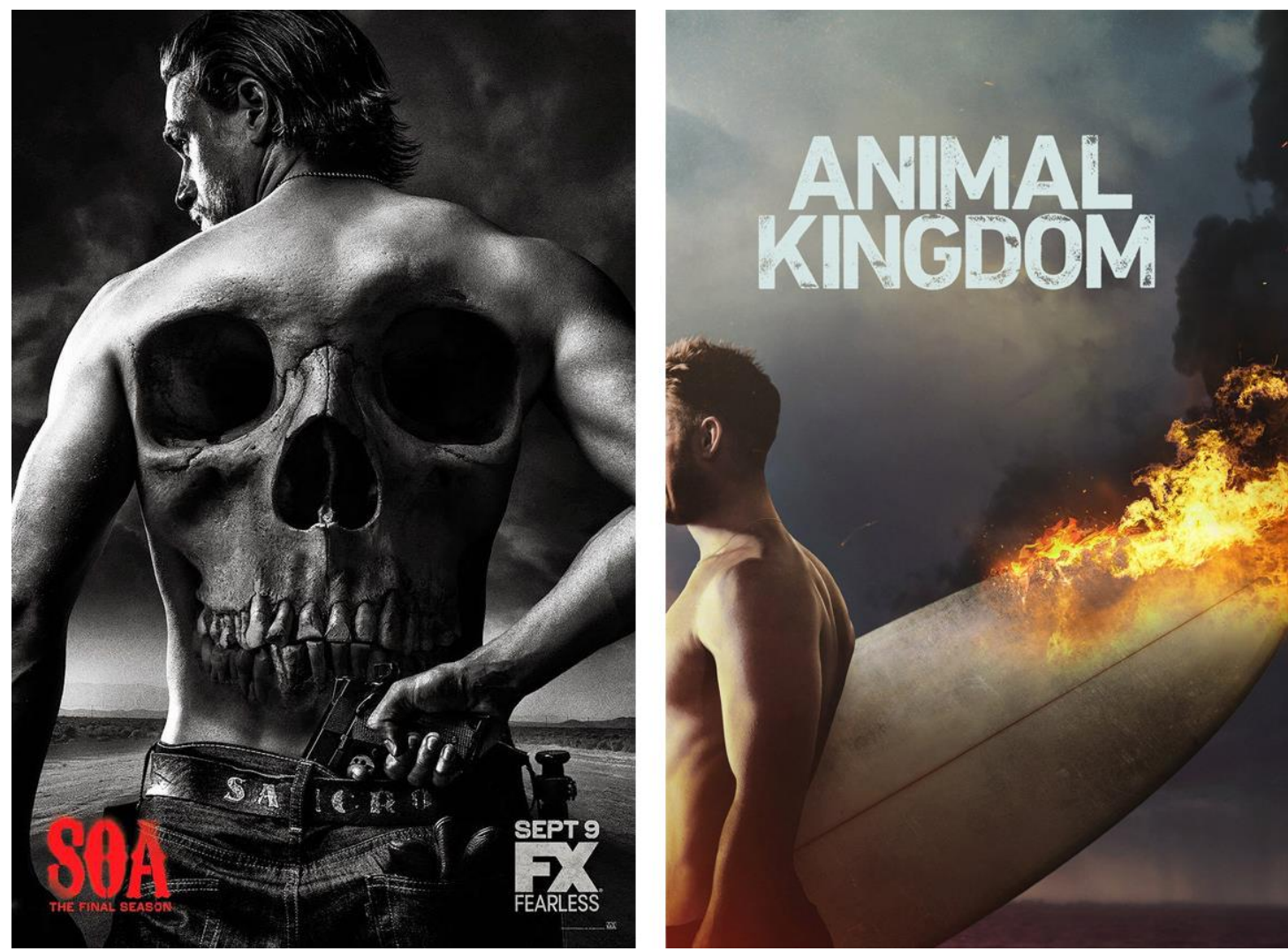

Figura 2. Izquierda: póster promocional de la sexta temporada de la serie Sons of Anarchy. Kurt Sutter [Productor], Estados Unidos, SutterInk, Linson Entertainment, FX, 2012. Derecha: póster promocional de la primera temporada de la serie Animal Kingdom. Liz Watts [Productora], Estados Unidos, John Wells Productions, Warner Horizon Television, TNT, 2016

\section{Barbarie y semiótica de la cultura}

Anclado en un imaginario topológico, Yuri Lotman (1996[1984]) reconoce que la cultura es un sistema complejo de textos en constante interrelación. Una hipótesis insistente en el semiólogo es que este intercambio cobra vida gracias al carácter delimitado de la esfera cultural: una frontera que supone "un dominio de actividad semiótica elevada, en la que trabajan numerosos mecanismos de 'traducción metafórica', que 'trasiegan' en ambas direcciones los textos" (1998[1993]: 150). La lectura del teórico es que, aunque dicha frontera otorgue homogeneidad e individualidad respecto a otras culturas, anuncia también un espacio donde los procesos y los cambios ocurren más activamente, con arreglo al rasgo particular de que las periferias comportan siempre el mayor dinamismo. Por ello, de categoría geopolítica y borde 
infranqueable, la frontera deviene entonces una aduana semiótica cuya naturaleza (adaptativa, traductora y, por ende, creativa) permite entender cómo los sistemas culturales procesan la información, al tiempo que tratan con su exterioridad (Lotman, 1996[1984]).

Ahora bien. La idea que preside en el proyecto lotmaniano es que la frontera viene a exponer uno de los pares binarios fundamentales, pivote sobre el cual se construye toda identidad cultural: "nosotros" vs. "Ios otros". Desde esta perspectiva, en un intento por describir su historia, los sistemas tienden a considerar que la "cultura propia" es la única existente, mientras que los mundos del otro lado de la frontera (como, por ejemplo, aquellos bárbaros) resultan siempre hostiles, caóticos y, por ende, no-culturas. Bajo el supuesto de que, al establecer sus límites, se crea no solo la propia organización interna, sino además la desorganización externa, Lotman asume entonces que la Antigüedad necesitaba "construir" los bárbaros. Según advierte,

\begin{abstract}
daba lo mismo que estos "bárbaros", en primer lugar, pudieran poseer una cultura mucho más antigua y, en segundo lugar, desde luego, no representaran un único todo, y formaran una gama cultural que abarcaba desde altísimas civilizaciones de la Antigüedad hasta tribus que se hallaban en un estadio muy primitivo del desarrollo. No obstante, la civilización antigua solo pudo tomar conciencia de sí misma como un todo cultural después de construirse ese, por así decir, mundo "bárbaro" único, cuyo rasgo distintivo fundamental era la ausencia de un lenguaje común con la cultura antigua (1996[1984]: 29).
\end{abstract}

En otras palabras, lo que evidencia el término genérico "bárbaro" es un mecanismo de autodescripción, funcional para sostener una identidad que se opone a una multiplicidad de alteridades, leídas como conjunto común. La frontera con el bárbaro esboza efectivamente la traducción metafórica de una situación fundamental de la cultura occidental: la existencia sociopolítica de ciertos sujetos como formas no reconocibles que, no obstante, le permiten a los sistemas "autoreconocerse". Lotman proseguirá, concluyendo que

lo 'bárbaro' es creado por la civilización, y esta lo necesita tanto como se necesita a sí misma (...) No importa si la cultura dada ve al 'bárbaro' como un salvador o como un enemigo, como una sana influencia moral o como un caníbal perverso, siempre está tratando con una construcción hecha en relación a su propia imagen invertida (1990: 52, la traducción es nuestra).

Advertimos que esta "imagen invertida" (que remite a la larga tradición de oponer barbarie a civilización, inaugurada por el pensamiento griego, pero luego replicada incansablemente por la 
historia de la cultura occidental, Cfr. Todorov, 2014 :29-39), refiere a aquel paradigma histórico que determina la identidad cultural como sinónimo del orden, el progreso y el máximo estadio de la evolución cultural, puesto que "civilizar es sacar a algo o alguien de un estado bárbaro o salvaje, instruyéndole en las artes de la vida de modo que pueda progresar en la escala humana" (Cebrián, 2017).

Asimismo, se trata no solo de desplazar lo bárbaro a lo no-cultural, sino más específicamente al lugar de lo animal: a esa zona fronteriza donde las especies no-humanas y el otro-cultural pierden la nitidez de sus formas, en tanto alteridades irreductibles para los sistemas. Porque, en su salvajismo, el bárbaro corporiza todo un imaginario sobre un otro animalizado que ha amenazado asiduamente al orden cultural. Nos referimos a una operación semiótica que ha permitido aludir a seres fantásticos (como, por ejemplo, ogros u orcos) y a pueblos históricos por igual, reconociéndolos como "salvajes" y, por ende, como figuras situadas al margen de la civilización. Aunque sus diferentes ramificaciones requieren de una historización particularizada (así, mientras el bárbaro no ha sido civilizado, el buen salvaje debe serlo pues es la sociedad la que pervierte al hombre), existen elementos comunes que componen un modelo descriptivo sobre el cual las culturas elaboran estereotipos externos, pero, como bien observaremos, también internos.

De modos más o menos explícitos, uno de estos elementos remite a la forma de composición "tradicional" del bárbaro: la horda invasora. En tal sentido, la metáfora de la "manada" da clara cuenta de una óptica bajo la cual el bárbaro se ha asimilado a una suerte de instinto gregario que, al tiempo que impulsa hacia la identificación recíproca entre los sujetos, termina estigmatizando y reduciendo ciertas comunidades a la homogeneidad animal. En otras palabras, en la búsqueda de la uniformidad y la estandarización, la cultura opera a través de un mecanismo descriptivo, donde la manada aparece como nomenclatura privilegiada, reconociendo su isomorfismo con formas históricas tales como el clan o la tribu. Aludimos a comunidades que, a los ojos de "lo civilizado", se comprenden como estadios evolutivos "previos": sociedades cerradas sobre sí mismas que autores como Edgar Morin definen en términos de micro-especies (2005[1973]: 205). A esta puntualización conceptual remitiremos a lo largo de nuestro recorrido puesto que, en los derroteros del imaginario cultural, el bárbaro se concretiza mediante variadas expresiones de un cuerpo colectivo en el cual la subjetividad individual que parece no ser "propia", sino parte de un tejido social.

Frente a este panorama, nuestra hipótesis de lectura sostiene que, al atender a su funcionamiento, lo bárbaro puede ser comprendido como un mecanismo de autodescripción complejo: una operación ideológica que es funcional tanto para imponer un conjunto de 
representaciones históricas del bárbaro, como también para ponerlas en discusión. No lo pensamos, por lo tanto, como una descripción exclusiva a una tensión de la Antigüedad, sino más bien como un operador cultural sumamente activo, como una lógica de regulación ideológica en nuestras sociedades occidentales contemporáneas que rápidamente se asumen a sí mismas como racionales, pero que insisten en interrogarse por estos lugares comunes con lo animal.
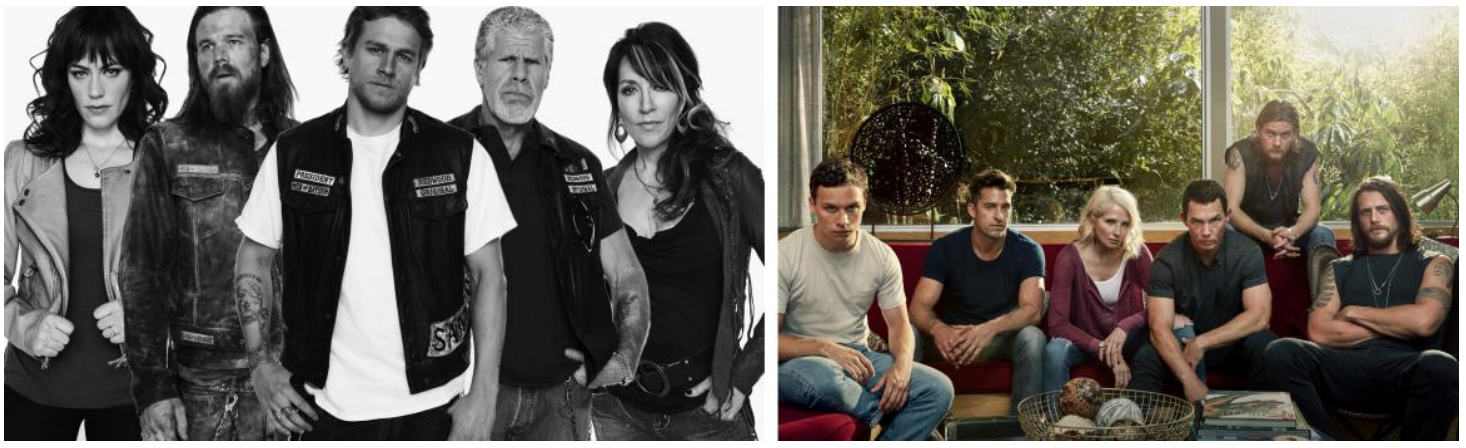

Figura 3. Izquierda: Imagen promocional de Sons of Anarchy, exhibiendo los personajes protagonistas que componen la filial californiana. Kurt Sutter [Productor], Estados Unidos, SutterInk, Linson Entertainment, FX, 2010. Derecha: Imagen promocional de Animal Kingdom, que muestra la familia Cody. Liz Watts [Productora], Estados Unidos, John Wells Productions, Warner Horizon Television, TNT, 2016.

Asimismo, no dudamos en afirmar que estas formas del bárbaro continúan irrumpiendo, principalmente en el arte, orden que ha tomado este lugar para dilucidar incansablemente qué se esconde dentro de esta condición de alteridad colectiva. Por ello, nos orientaremos seguidamente a problematizar de manera exploratoria dos series de TV que retoman una alusión a la manada bárbara, no mediante una referencia directa, sino en torno a aquello que junto a Lotman llamamos una traducción metafórica, sintetizadora de matices de sentido sociohistóricos. Nos referimos a Sons of Anarchy y Animal Kingdom, narrativas que, producidas en los últimos años, ponen en cuestión la manada bárbara. Puesto que el caudal más amplio de series proviene de la maquinaria ideológica de los Estados Unidos, referente hoy ineludible en estos textos artísticos, atenderemos entonces a un bárbaro que es problematizado desde un "lente estadounidense" (Carrión, 2014: 145).

Debemos interrogarnos, no obstante, cómo aplicar metódicamente la categoría de autodescripción lotmaniana al análisis de un objeto de tan complejo como la serie televisiva. Como hemos señalado inicialmente, la teoría de Lotman propone al texto como su noción central, especificando que toda textualidad (re)produce modelos de lo real: ello es, modeliza coordenadas sociohistóricas mediante sus operaciones tanto de forma como de contenido. 
Reconociendo su deuda teórica con el pensamiento de Mikhail Bakhtin, Lotman asumirá que los personajes protagonistas son los encargados de vehiculizar estos modelos de mundo y trazar, con ello, una "descripción" del sistema cultural por tanto "caracteriza el lugar, la posición y la actividad del hombre en el mundo que lo rodea" (Lotman, 1998[1969]: 99). En otras palabras, la hipótesis lotmaniana es que los protagonistas se emplazan como centros argumentales que refractan los valores que el texto en su totalidad quiere transmitir, como también devienen "puntos de vista" que recuperan la imagen que la cultura ofrece de sí misma en un momento dado.

Este supuesto nos permite definirlos como condensadores semánticos que, inscriptos en la estructura narrativa (o, al decir de Omar Rincón, "el flujo del macrorrelato", 2006: 174), transmiten y problematizan complejas autodescripciones. En consecuencia, nos abocaremos al estudio de personajes en su representación audiovisual, siguiendo el "criterio semántico y semiológico" propuesto por François Jost para el análisis de las series televisivas (2015: 14). Se trata, según la mirada del estudioso, de atender elementos narrativos que hacen a la construcción de sentido del personaje: datos biográficos y de la personalidad (a través de intervenciones discursivas íntimas -monólogos- y externalizadas -diálogos-), la presentación visual (su descripción y autopercepción física), el mapa de relaciones con otras subjetividades y la ubicación en el orden cultural que propone cada serie. En conjunto, estos aspectos dan cuenta de un modo de subjetivación que compone aquello que Jost define como el "carácter" de los personajes seriales, "en el doble sentido que el idioma inglés da a esta palabra: 'personaje' y 'carácter'” (2015: 10).

\section{Acerca de Sons of Anarchy y Animal Kingdom}

Creada por Kurt Sutter, Sons of Anarchy es una serie emitida entre 2008 y 2014 por la cadena estadounidense FX, centrada en un grupo de moteros que habitan en Charming, poblado ficcional de California. La banda constituye la filial californiana de una célula mayor con sede en Irlanda del Norte, su lugar de descendencia y de procedencia del principal negocio que los caracteriza: el tráfico de armas (que permite, además, el sostén económico del largo conflicto civil irlandés). De modo que, en líneas generales, el Club de Moteros Los Hijos de la Anarquía (nombre que recibe la organización, fundada en los años '60 y sintetizada bajo la sigla SAMCRO) conjura, a primera vista, dos grandes vectores: el problema interétnico/intercultural entre los guetos estadounidenses de diferentes ascendencias (irlandeses, pero también 
aquellos mexicanos, chinos y afroamericanos) y la criminalidad internacional que se desarrolla en las periferias mismas de los Estados Unidos a través de estas figuras "forasteras" [outlaws] (102) (1).
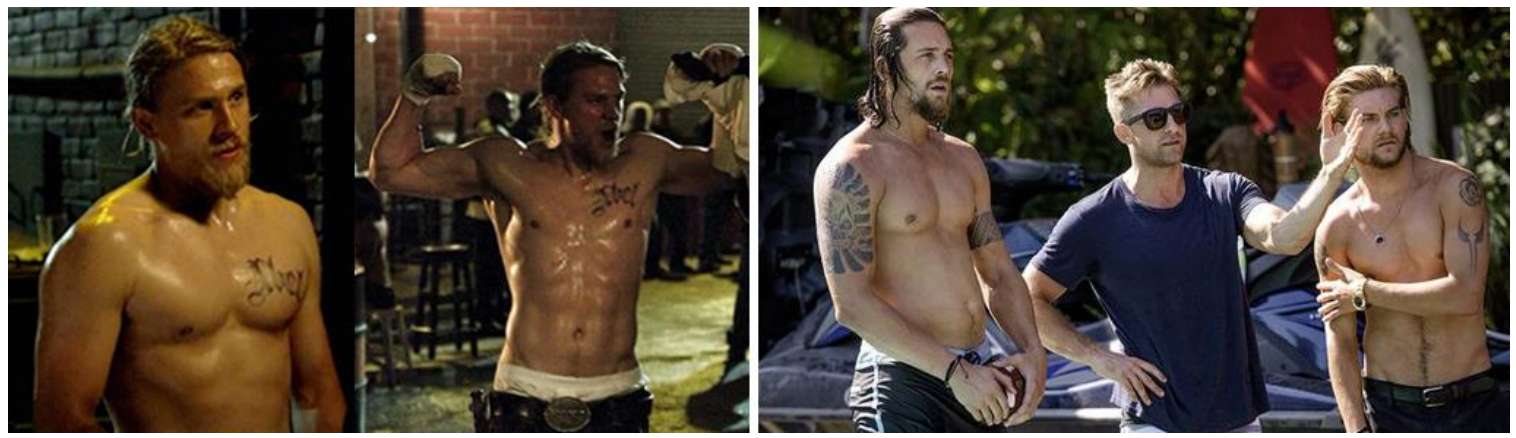

Figura 4. Izquierda: fotogramas del protagonista de Sons of Anarchy, Jax Teller (Charlie Hunnam) y su exhibición constante de los emblemas de SAMCRO. Kurt Sutter [Productor], Estados Unidos, Sutterlnk, Linson Entertainment, FX, 2009. Derecha: fotograma de los miembros de la familia Cody, en una exposición análoga. Liz Watts [Productora], Estados Unidos, John Wells Productions, Warner Horizon Television, TNT, 2016.

Por lo demás, en los avatares de sus siete temporadas, la trama se focaliza en Jax Teller (Charlie Hunnam), actual vicepresidente del club e hijo de quien otrora fuera su fundador, John Teller. Influido por la presión simbólica que ejerce su fallecido padre, la asunción al liderazgo aparece en el protagonista como un legado familiar que obligadamente debe cumplirse. Sin embargo, desde el comienzo de la serie, Jax muestra cierto estado de inconformidad con el rol, crisis personal desencadenada a partir del hallazgo de un manuscrito escrito por su antecesor y donde se critica que aquello que, en sus inicios comienza como una "rebelión social", paulatinamente deviene una banda de delincuentes. Entrelazada con los conflictos de una exmujer drogadicta y un hijo que nace prematuro, la historia de Jax enfatiza en la conflictiva relación con su autoritaria madre Gemma (Katey Sagal) y Clay (Ron Perlman), su pareja y actual presidente del Club. Ambos esconden un secreto que será develado con el correr de las temporadas: la verdad en torno a la muerte del fundador de SAMCRO. Así, las traiciones, las conspiraciones y el temor a que el recién nacido tome el mismo camino de corrupción (problemática que asoma en el primer episodio, para resolverse en el final del relato) hacen de Sons of Anarchy una suerte de tragedia serial que la crítica ha definido como "Hamlet en motocicleta" (Dunn y Eberl, 2013: ix).

Dejamos un momento Sons of Anarchy para introducir el segundo texto: Animal Kingdom, narrativa a la que TNT dio luz en el año 2016 y que espera, en tiempos próximos, su tercera temporada. Basada en el filme homónimo de 2010, la serie ficcionaliza el reconocido caso de 
los Pettingill, familia australiana que fuera popular por hostigar con sus crímenes a la ciudad de Melbourne durante casi una década. En su versión serial, la historia se emplaza en la Costa Oeste de los EEUU y las rutas californianas de Sons of Anarchy se verán reemplazadas por las playas del Orange Country. En este contexto, la trama se centrará en Joshua "J" (Finn Cole), adolescente que ha perdido su madre por una sobredosis y encuentra resguardo en el hogar de su abuela, Janine "Smurff" Cody (Ellen Barkin). Allí, deberá convivir con sus cuatro tíos: Craig (Ben Robson), un surfista adicto a las drogas; Dare (Jake Weary), el más joven de los hermanos y que esconde una homosexualidad fuertemente reprimida; Pope (Andrew Hatosy), el mayor, con problemas depresivos y recién liberado de prisión; y Baz (Scott Speedman), quien en realidad no guarda lazos sanguíneos con el resto, pero ha sido adoptado desde temprana edad hasta devenir casi un líder.

$Y$ decimos casi, en tanto Smurf es quien comporta la totalidad de las decisiones que involucran un amplio caudal de ilegalidades. Así, lejos de responder a una familia tradicional, los Cody componen un clan criminal dedicado a la realización de aquello que llaman "los trabajos": robos, secuestros, estafas y venta de drogas son una fuente de ingresos que luego será lavada por la matriarca a través de bienes inmobiliarios ficticios, mientras los miembros restantes reciben una suerte de "mesada" por su labor como mano de obra. En tanto nuevo miembro de la familia e impulsado por la sospecha de que alguno de sus tíos podría ser su padre (asomando, con ello, un sesgo de incesto que la serie aún no ha terminado de resolver), J tiene que "aprender el camino" (101). En palabras de Smurf, se trata de

algo que nos involucra a todos. Eres parte de esta familia ahora. Vas a ver cosas, oír cosas, que necesitan quedarse en esta familia (...) Nunca lastimamos a nadie, esa no es la forma en que trabajamos. Tampoco tomamos riesgos estúpidos. No somos codiciosos (...) No hay secretos en esta familia. No entre nosotros y, especialmente, no conmigo (102).

A nuestro entender, Sons of Anarchy comparte una comprensión de comunidad muy similar, aunque la idea de familia que propone no responde a la exclusividad de los vínculos sanguíneos. Se trata, más bien, de una forma colectiva fundada por el mismo John Teller, quien asumió que "su visión era una hermandad, una familia" (101). Interesa señalar que el Club conforma una micro-sociedad compuesta por exsoldados devenidos criminales, cuyas familias adhieren a esta gran comunidad. En los Hijos de la Anarquía, ellos no solo obtienen protección e ingresos económicos, sino que además parecen haber encontrado su lugar en el mundo para afrentar los traumas de posguerra (cuestión que, vale destacar, recupera activamente esta discusión recurrente en los EEUU). No obstante, lejos de ser una "anarquía", 
el grupo respeta un riguroso sistema normativo cuyos principios se basan en la lealtad y el honor entre los miembros, perspectiva homóloga a Animal Kingdom, aunque bien dichos códigos parecen verse reemplazados por el respeto y el temor hacia la madre.

En síntesis, estas narrativas (que además comparten cierta estructura de policial) ponen en escena, paralelamente, un amplio número de problemáticas contemporáneas: la violencia, la criminalidad, las formas del vigilantismo, la corrupción, la trata de personas y el tráfico de armas dan, de manera ejemplar, clara cuenta de la complejidad de estos textos que aspiran a exhibir una suerte de hedonismo colectivo. Aparece también otro signo en común: se trata de una semántica de lo bélico que atraviesa fuertemente a ambos relatos, y manifiesto en un amplio caudal de metáforas que conciben a las mujeres como botines, a las motos y los autos como sinécdoques de estos soldados del asfalto y a los escenarios de la cotidianeidad como campos de guerra en donde se encuentran los diferentes bandos con las fuerzas de la ley. Habitadas por episodios de agresión extrema, de cruentos asesinatos y disparos a plena luz del día, los diferentes paisajes de California devienen, en ambos textos, espacios privilegiados para la recuperación de estos motivos acuciantes de nuestra actualidad, ficcionalizados mediante el desenvolvimiento de órdenes familiares no tradicionales en los cuales prima, ante todo, la comunión de los sujetos.

\section{Los sentidos del bárbaro serial}

Con base en las consideraciones anteriores, resulta significativo que estas complejidades familiares y sistemas de tensiones entre ilegalidad y fraternidad aparezcan captados a través de una metáfora que aparece insistentemente en las series: ante la mirada de la restante población, los Coby y los Hijos de la Anarquía son, sin lugar a dudas, "basura blanca y bárbara" [white-trash barbarians] (402). Cabe destacar que, en estos contextos la expresión "basura blanca" adquiere otras connotaciones, en tanto se desplaza de su clásico matiz peyorativo (índice de una clase socioeconómica baja) para dar lugar, con ello, a un gesto despectivo más general que aplica a una parcela cultural, y que ha brotado fuertemente en los recientes años. Según la propuesta del sociólogo Matt Wray (2006: 7), se trata de pensar la "basura" como un amplio estereotipo cuyas resonancias, siempre estigmatizantes y discriminadoras, apuntan a prácticas que la sociedad estadounidense excluye de un canon de "normalidad" cultural. A ello debe añadirse el hilvanado con la metáfora del bárbaro, cuya inclusión no solo pone de manifiesto la activación de una memoria occidental (aquel imaginario del bárbaro como sujeto 
caótico, al cual aludiéramos líneas arriba), sino además la puesta en relieve de su descripción gregaria: es decir, el devenir manada.

Conviene preguntarnos, en este punto, qué implicancias tiene esta lectura de la manada y por qué se vincula con la construcción de estas familias ficcionales. $Y$, en función de ello, quisiéramos llamar la atención acerca de la propuesta Éric Michaud quien, en su estudio Las invasiones bárbaras. Una genealogía de la historia del arte (2017), se interroga por qué, en el curso de la memoria occidental, los pueblos germanos han sido representados como un conjunto imaginario que habría permanecido idéntico durante siglos. Dicho de otro modo, el estudioso problematiza un intento cultural por sintetizar un milenio de historia de sociedades que, aún heteróclitas, aparecen en el imaginario como una única comunidad, reconocida como "bárbara".

Aunque, en la actualidad, los historiadores no duden en afirmar que las invasiones al Imperio romano no fueron emprendidas por un mismo pueblo (que, además, tenía poca relación con lo germano) y que comprenden múltiples episodios dispersos y con diferentes motivaciones, Michaud entiende que aquí han operado una "ficción de unidad racial" (2007: 12): representaciones reduccionistas que se construyen con base en dos rasgos fundamentales, como son la homogeneidad y la continuidad étnica. A ello debe añadirse que, en el discurrir de los siglos, el lazo de sangre supuso el vector que permitía definir las interrelaciones que constituían históricamente a pueblos, clanes, tribus, etnias y, más tarde, naciones, en tanto "brazo" horizontal y vertical que, según intuye Éric Michaud, posibilitaba aunar la diacronía y la sincronía de las comunidades. Por lo cual, según la hipótesis del autor, la permanencia de la nomenclatura cultural de "bárbaro" esconde, en su interior, una fuerte problemática en torno a la herencia, ya que

el discurso de la sangre, como hoy el del gen, se asienta sobre una indivisibilidad fundamental: ya se apliquen a los humanos o a los objetos artísticos, ambos relacionan siempre las diferencias visibles entre los cuerpos con causas naturales que permanecen ocultas, pero que estarían encargadas de asegurar sin fallar la transmisión de las diferencias. De manera que esos discursos afirman no que la cultura está en la naturaleza sino que ella procede de la naturaleza (2007: 25, cursiva en el original).

De modo que nos inclinamos a pensar que la pregunta por el bárbaro remite a un interrogante por la homogeneidad racial y, más específicamente, por la herencia biológica de caracteres físicos y psicológicos que habilitan el reconocimiento de ciertas poblaciones históricas. En tal sentido, no resulta ilógico que, en un nuevo desborde de las hordas bárbaras, la pregunta por 
la herencia somática aparezca nuevamente, esta vez para poner en cuestión una problemática acuciante de la contemporaneidad como lo es el orden familiar. De ello dan clara cuenta estas series que guardan cierta estructura del género dramático y que ponen en el centro de sus argumentos la constitución de familias "anormales": guetos dedicados a la criminalidad del asfalto (Sons of Anarchy) y aquella urbana (Animal Kingdom), pero que priorizan un concepto de comunidad que va más allá de los lazos sanguíneos. Esta fluencia grupal de "anormalidades" no es casual, si consideramos que los estudiosos coinciden en advertir que las recientes narraciones seriales traen consigo innumerables personajes "anormales", esbozando un estado de la cuestión sobre las condiciones sociopolíticas en un corte sincrónico de la cultura (Carreras Lario, 2014; Jost, 2015). En el caso de Sons of Anarchy y Animal Kingdom, dicha anormalidad toma la forma de una manada, atravesada fuertemente por la metáfora de un bárbaro que aparece como mecanismo de autodescripción privilegiado para escenificar una crítica acuciante: el modelo canónico de familia y su validación como institución social contemporánea.

Con el objeto de arrojar luz a este supuesto, podríamos señalar algunos aspectos que arrostran cómo ello toma forma en los textos que nos convocan aquí. Lo primero a delimitar es que, en un nivel superficial, esta lectura de la comunidad bárbara se reafirma mediante la recurrencia a aquello que, anteriormente, hemos definido como una estética bárbara (Gómez Ponce, 2016): rasgos en la representación corporal de los personajes que reorganizan un imaginario cultural sobre el bárbaro y que combinan, indiscriminadamente, variados estereotipos que van desde el vikingo hasta el Homo sylvestris. Focalizaríamos, entonces, en el estilo de sus protagonistas, quienes comparten características, tales como los cabellos largos, la repetición de los torsos desnudos y la exhibición constante de los tatuajes que ello permite (incluso resulta de interés que las introducciones de ambas series se centren en mostrar estas inscripciones corporales: mientras Sons of Anarchy expone los nombres del elenco a través de los tatuajes en el cuerpo, Animal Kingdom intercala con escenas del proceso de tatuado). Además, más allá de las similitudes físicas, las series ponen de manifiesto un repertorio de símbolos exclusivos para cada manada: mientras el chaleco, los tatuajes y las motocicletas suponen signos que confirman la pertenencia a SAMCRO, la posesión de autos de alta gama, las armas de alto calibre, los deportes extremos y la pasión por el surf aplican a los Cody. La combinación de estos aspectos desprende que, para pertenecer a la manada, resulta necesario compartir una serie de gestos, prácticas y rasgos estéticos que den cuenta de la uniformidad. Se trata, además, de una lógica alentada por quienes detentan el poder, incluyendo también respectivos ritos de iniciación que habilitan la permanencia en los grupos: así, mientras Sons of Anarchy 
somete a los nuevos miembros a una serie de pruebas (coronando con el tatuaje emblemático de la filial), Animal Kingdom opta por una ceremonia quizá menos simbólica, en tanto J pasa a "formar parte" a partir de su primer crimen.
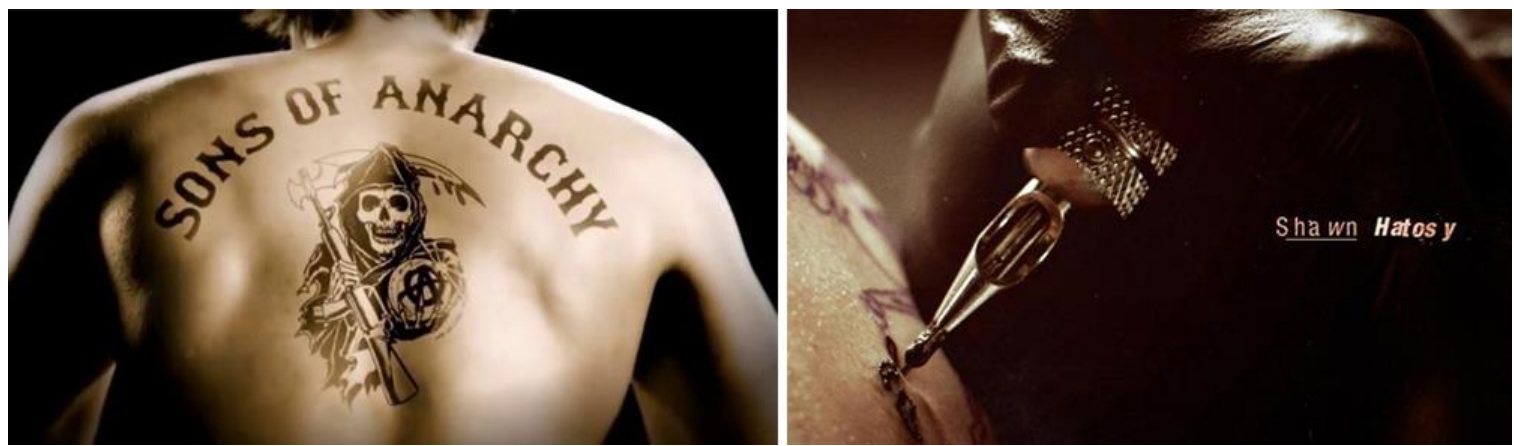

Figura 5. Izquierda: fotograma de los tatuajes visibles en la presentación de la serie Sons of Anarchy, Kurt Sutter [Productor], Estados Unidos, SutterInk, Linson Entertainment, FX, 2009. Derecha: fotograma de la presentación de la serie Animal Kingdom. Liz Watts [Productora], Estados Unidos, John Wells Productions, Warner Horizon Television,

TNT, 2016

Por lo demás, considerados en conjunto, estos aspectos arrostran el modelo de masculinidad que domina en ambos textos. En este marco, los personajes se perciben dentro de una red intersubjetiva que habilita o prohíbe comportamientos, homogeneiza valores y colabora en la conformación de una identidad masculina que hibrida estereotipos, como el rebelde, el motero, el reo, el criminal o el fratmen. Al tiempo que refracta una idea de comunidad, la cohesión de estas prácticas sociosexuales subraya un modelo de sujeto masculino que debe "hacer lo correcto por la familia", pues las narrativas repiten asiduamente que "Ios hombres se hacen cargo de los negocios" (101). Referimos a características propias de sociedades regidas por la falocentría, en donde los respectos líderes de la manada (tanto Jax como J), corporizan una forma tradicional de poder que se homologa a una imagen de padre de familia.

No obstante, lo interesante es que, en un análisis más profundo, las series dejan entrever que, en esta apropiación de la condición masculina, existe cierta contradicción. Porque, finalmente, estos responsables de las hordas aparecen casi como figuras patriarcales simbólicas, en tanto quienes controlan y dirigen las redes de poder son las mujeres. Así, mientras en Animal Kingdom este rol es asumido por Smurf, en Sons of Anarchy aparece Gemma como aquella quien, por detrás del hombre dominante, digita las decisiones y asegura la continuidad del legado. Ambas muestran personalidades que no se ven limitadas por su condición de mujer y cuyos pasados permanecen ocultos al espectador hasta casi finalizar las tramas puesto que, al develarse, se pondría de manifiesto el amplio caudal de intervenciones maquiavélicas que han 
cometido para asegurar la continuidad familiar. $\mathrm{Y}$, bajo estos fuertes órdenes matrilineales (porque, aunque el sujeto masculino represente el poder, su adquisición siempre estaría adhiriendo a la herencia maternal, Aranzadi Martínez, 2008), yacen complejos dispositivos de control y regulación que aseguran la unidad de estas manadas, sin importar el costo.

De ello da cuenta cómo, en Animal Kingdom, las fiestas, las drogas, los deportes extremos, los lujos y el sexo casual son prácticas impulsadas por esta controversial madre que no permitió a sus hijos llevar el apellido paterno, que irrumpe en su intimidad y los incita a exhibirse desnudos, y que no tolera otra figura femenina en la familia: según advierte una de sus nueras, Smurf "le dará la espalda a cualquier mujer cuando le crezcan las tetas" (103). De manera casi paradójica, estas prácticas del exceso advienen entonces formas de control por parte de estas madres, resonando aquí las hipótesis de Michel Foucault (2014: 15) para quien nos hallaríamos ante un poder que se ejerce en sujetos que se piensan libres, dado que ello resulta necesario para poder gobernarlos. En tal sentido, tanto Smurf como Gemma habilitan un margen de libertad sobre sus hijos, aunque finalmente este termine siendo operando a través de formas subrepticias de control como, por ejemplo, el manejo de lo emocional. En ambos casos, diremos que la mecánica dominante subyace en la intervención de la culpa que estas madres movilizan, movilizando constantemente a que sus respectivos hijos asuman "responsabilidades" familiares: Jax y $\mathrm{J}$ cargan consigo la obligación de continuar con el legado de la manada, como también de mantener unida la comunidad y regularla según los ordenamientos que sus madres sugieren de modos más o menos explícitos.

De modo que, si bien esta descripción del bárbaro supone una performance dominante de lo masculino, se tensiona, sin embargo, con otra jerarquía de corte matrilineal: protagonistas que asumen el rol de mujer y madre, pero también de aquellas capaces de aunar las comunidades, dado que "pueden hacer o romper un club si así lo desean", como bien advierte Sons of Anarchy (104). En un enfrentamiento constante por determinar quién asume el lugar de líder de la manada y, por ende, custodio del hogar, las narrativas tergiversan una tradicional cartografía de los géneros, al friccionar estas personajes con los respectivos hijos que quieren rebelarse y romper con la tradición para formar su "propia familia" porque, en estas manadas, la condición criminal se ficcionaliza como rasgo hereditario $y$, posiblemente, las nuevas generaciones no puedan salvarse de este legado. En esta lectura, radica un aspecto de interés para problematizar, en futuras investigaciones, como estos modelos contemporáneos de lo familiar ponen en cuestión las construcciones de los géneros.

Aún a riesgo de simplificar, es posible decir que, en estas complejidades y sistemas de tensiones, el núcleo de ambas historias evoca la metáfora del white-trash barbarian, para 
explicitar una misma preocupación: la importancia que adquiere la familia como concepto, como red intersubjetiva que supera los lazos consanguíneos. Por lo demás, esta interpelación constante estaría exponiendo una pérdida de confianza en este sistema ideológico de gran trascendencia para los Estados Unidos. Y aunque de ningún modo sería pertinente desviar aquí la discusión, vale señalar que ello remite a este imaginario del American Way of Life: el conjunto de creencias colectivas que definen prácticas de lo pensable y que devienen basamento para la formación de una identidad nacional, según sugiere el historiador Jim Cullen (2004). Junto a otros elementos constituyentes (el éxito económico, las realizaciones educacionales, la libre expresión y las diásporas migratorias), en el imaginario cultural, esta ideología llegaría a su máximo esplendor mediante la construcción de un "lugar mítico" específico (Cullen, 2004: 9): un modelo de familia que corporiza este Way of Life y donde la posesión de hogar, trabajo e hijos culmina en uno de los escenarios más refractados por el arte, como es el "sueño suburbano". En sus derroteros, parecería que ambas narrativas seriales aspiran a mostrar que la importancia radica en concretar este pilar "tradicional", sin interesar cuál es su costo. En la disputa entre roles masculinos y femeninos, entre paternidad y maternidad, aquello que se pone en relieve es la asunción de un rol unificador y protector, pues lo que debe prevalecer, a todo lugar, es la comunidad. En tal sentido, Sons of Anarchy y Animal Kingdom son narraciones que, a través de esta semiotización de la manada, convocan un estado de la cuestión sobre nuestra contemporaneidad y la trascendencia que adquiere la familia como concepto cultural.

\section{A modo de conclusión}

Nuestro trabajo pretendió atender a uno de los intentos más recientes del bárbaro por escenificar otra reducción a la homogeneidad: la constitución de la familia, de sus formas no convencionales y no tradicionales, poniendo en cuestión así uno de los pilares fundamentales de la constitución identitaria de los Estados Unidos. $Y$ es posible conjeturar que, en tanto ejemplos paradigmáticos, Sons of Anarchy y Animal Kingdom exponen el quiebre en los cimientos de este sistema ideológico fundamental (el Sueño Americano), como una fractura en el orden de la cotidianeidad que figura como una condición no reparativa. Dicho de otra manera, referimos a series de TV que, en sus operaciones de significación y en sus modos de trazar límites de lo "normal", están exhibiendo una problemática acuciante sobre una conformación ética y moral de lo familiar. Por lo cual, en estas producciones masivas que han invadido el consumo contemporáneo, se halla una proliferación de sentidos para comprender la 
realidad y para volver a pensar cómo las semióticas del bárbaro, motivo de larga tradición occidental, deviene óptica pertinente para atender un amplio cúmulo de aspectos socioculturales. En tal sentido, las series seleccionadas muestran solo un acercamiento a este cuestionamiento que nos impulsa a continuar indagando, en futuras investigaciones, sobre ciertos recorridos estéticos que codifican, mediante una lente hollywoodense, crisis sociales y políticas.

Por lo demás, no dudamos en afirmar que el bárbaro adviene, en estas productividades, como una efectiva descripción cultural que continúa problematizando un amplio caudal de subjetividades-otras y concretándose entonces como una frontera semiótica: metaforiza prácticas entre el afuera y el adentro cultural, entre la norma y lo prohibido. Pero, tal como las tribus bárbaras al servicio de los imperios (ejemplo recurrente en el edificio teórico de luri Lotman), el bárbaro, en su insistencia actual, sostiene esta frontera: muestra el límite y parece devenir, en consecuencia, custodio de "lo normal", sujeto que el sistema construye para señalar, en esta oportunidad, un ordenamiento que remite a la esfera familiar. En esta reiteración de lo bárbaro como lugar de enunciación en las narraciones actuales, nos atrevemos a afirmar que las formas artísticas son más efectivas porque presentan, en términos del semiólogo ruso, un modo más económico y más compacto para la transmisión de la información. Y, en esta economía, se hallarían puntos clave para asumir el desafío de seguir reflexionando sobre un bárbaro como recurrencia cultural quizá porque, como bien pensaba Voltaire, la civilización nunca suprimió la barbarie, sino que la perfeccionó.

\section{Notas}

(1) La codificación para anotar las citas de las series es la siguiente: la primera cifra indica la temporada y las dos siguientes, el número de capítulo. Por ejemplo, 203 (tercer episodio de la segunda temporada). Asimismo, las traducciones de los diálogos al español son nuestras.

\section{Bibliografía}

Bartra, R. (2001). "El mito del salvaje". En Revista Ciencias, Nro. 61, México, pp. 88-96.

Carreras Lario, N. (2014). "La creación de personajes en series norteamericanas": En Caldevilla Domínguez, D (ed.). Lenguaje y persuasión. Nuevas creaciones narrativas. Madrid: ACCI, pp. 85-100. 
Carrión, J. (2014), Teleshakespeare. Las series en serio. Buenos Aires: Interzona.

Cebrían, J (2017). "Barbarie, religión y progreso". En Diario El País. Recuperado de: https://elpais.com/diario/2006/09/17/opinion/1158444004_850215.html, acceso 30 de agosto de 2017.

Cullen, J. (2004). The American Dream: A Short History of an Idea that Shaped a Nation. New York: Oxford University.

Dunn, G. y Eberl, J. (2013). "Gotta Look this Life in the Eye". En Dunn, G. y Eberl, J. (eds.), Sons of Anarchy and Philosophy. Brains before Bullets. Oxford: Wiley Blackwell.

Foucault, M. (2014). Las redes de poder. Buenos Aires: Prometeo Libros.

Gómez Ponce, A. (2016). "El retorno de los bárbaros. Fronteras semióticas y desmitificación de complejos culturales en la figura del vikingo". En: Revista de Literaturas y Cultura Comparadas, Vol. 6. Pp. 2-15.

Gómez Ponce, A. (2017). Depredadores. Fronteras de lo humano y series de TV. Córdoba: Babel.

Jost, F. (2005). Los nuevos malos. Cuando las series estadounidenses desplazan las líneas del bien y del mal. Buenos Aires: Libraria.

Lisco, J. (2014). Animal Kingdom [Series de Televisión]. Estados Unidos: Jonh W. Productions, Warner Bros Television.

Lotman, Y. (1990). The Universe of the Mind. Londres: Indiana University Press.

Lotman, Y. (1996[1984]). "Acerca de la semiosfera". En Lotman, Y. La Semiosfera I, Madrid: Frónesis Cátedra, pp. 21-42.

Lotman, Y (1998[1969]). "Sobre el metalenguaje de las descripciones tipológicas de la cultura". En Lotman, Y. La Semiosfera III, Madrid: Frónesis Cátedra, pp. 93-123.

Lotman, Y. (1998[1993]). "La cultura como sujeto y objeto para sí misma". En Lotman, Y. La Semiosfera II, Madrid: Frónesis Cátedra, pp. 140-151.

Lotman, Y. (2000[1977]). "El lugar del arte cinematográfico en el mecanismo de la cultura". En Lotman, Y. La Semiosfera III, Madrid: Frónesis Cátedra, pp. 123-137.

Martínez, J. (2008). Introducción histórica a la antropología del parentesco. Madrid: Editorial universitaria.

Michaud, É. (2007). Las invasiones bárbaras. Una genealogía de la historia del arte. Buenos Aires: Adriana Hidalgo Editora.

Morin, E (2005[1973]). El paradigma perdido: ensayo de bioantropología. Kairós: Barcelona. Rincón, O. (2006). Narrativas mediáticas. Barcelona: Gedhisa. 
Sutter, K. (2008). Sons of Anarchy [Series de Televisión]. Estados Unidos: Sutter Ink, FX Productions.

Todorov, T. (2014). El miedo a los bárbaros. Barcelona: Galaxia Gutenberg.

Wray, M (2006). Not Quite White: White Trash and Boundaries of Whiteness. New York: Duke University Press. 